\title{
Middle ear malignant happened after lacrimal sac malignant
}

\author{
Qiang Li, Liang Zeng and Hongqun Jiang* \\ Department of Otolaryngology-Head and Neck Surgery, The First Affiliated Hospital of Nanchang University, Nanchang 330006, Jiangxi, P. R. China
}

\begin{abstract}
This paper reports a case of squamous cell carcinoma of middle ear that appeared after lacrimal sac malignant with an unusual clinical course.
\end{abstract}

\section{Case report}

A 57-year-old female presented with 2-years history of recurrent right epistaxis and epiphora who was diagnosed with squamous cell carcinoma of lacrimal sac in our hospital, after surgery and the subsequent treatments of chemotherapy and radiotherapy, the patient had a good recovery. However, approximately 30 months later, the patient started to have symptom of purulent with blood discharge from the right ear, gradual hearing loss and tinnitus. Pathological examination revealed the diagnosis of squamous cell carcinoma of the middle ear (SCCME). Lacrimal sac is a rare site of squamous cell carcinoma, and SCCME is also rare, SCCME happens after lacrimal sac malignant has been never described in the literatures.

\section{Introduction}

There has been no known reported case of aural metastasis from lacrimal sac malignant tumors, lacrimal sac tumors are uncommon tumors with approximately only 300 cases described in the literature [1]. The malignancy rate of all lacrimal sac tumors is $55 \%$ to $75 \%$. The most common malignant tumors are squamous cell carcinoma $[1,2] .50 \%$ of malignant of the lacrimal sac recur and of the mortality rate is more than $50 \%$ [3]. The risk factors of which include human papilloma virus (HPV) and human immunodeficiency virus (HIV). HPV has been implicated in the etiology of the lacrimal sac neoplasia [4]. Squamous cell carcinoma occurs in middle ear (SCCME) is also rare, only accounts for $1.5 \%$ of temporal bone malignant tumors [5]. Currently, the etiological factors of SCCME are unknown, but possible causes are chronic otitis media and HPV infection [6,7]. The manifestations of SCCME are atypical in early stage and similar to chronic supportive otitis media easy to be misdiagnosed. Surgery together with radiotherapy is the main treatment approach to middle ear malignancy $[8,9]$. Here we report the original and first case of a patient with squamous cell carcinoma of lacrimal sac might distant metastasis to the middle ear.

\section{Case history}

A 57-year-old female patient was admitted to our hospital 5 years ago, with recurrent right side epistaxis and epiphora in the past two years. Nasal endoscopy showed a cauliflower-like granulation tissue protruded from the inferior nasal meatus (Figure1a). A biopsy from this area showed a diagnosis of non-keratonizingsquamous cell carcinoma.
The eye movement and visual acuity were not disturbed. Palpation of the neck showed regional lymph nodes were unremarkable. A computed tomography (CT) scan of the head and neck showed soft tissue density lesions in right lacrimal sac and inferior nasal meatus did not show any evidence of bony erosion (Figure1b), and chest CT scan did not disclose any abnormalities. After discussion at the multidisciplinary consultation meeting, surgery for removal of lesions in lacrimal sac and right inferior nasal meatus was decided. The patient underwent medial maxillectomy and dacryocystectomy through a lateral rhinotomy approach and surgical margins were all negative. Intraoperative pathologic biopsy from lacrimal sac tumor revealed squamous cell carcinoma in situ (Figure2a). Immunohistochemistry staining of CK was positive and performed for HPV marker.In situ hybridization was positive for high-risk HPV strains 16,18 and negative for low-risk HPV strains 6 and 11. The patient was eventually diagnosed as squamous cell carcinoma of the lacrimal sac. Review of the magnetic resonance imaging scan for the surgical site taken soon after the surgical showed no evidence of local recurrence (Figure1c). The patient received postoperative chemotherapy and radiotherapy. No recurrence or metastasis was observed at the 12-month follow-up.

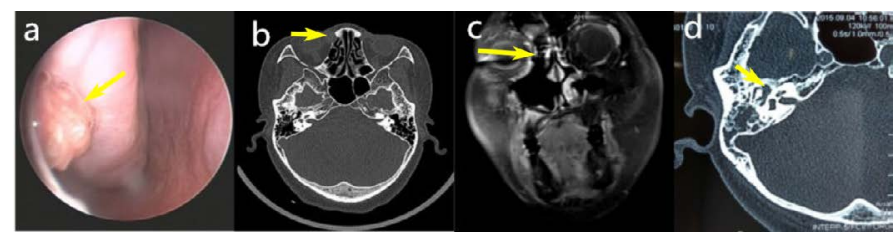

Figure 1. a) Endoscopic view showing a cauliflower-like granulation tissue protruded from the inferior nasal meatus. b) Axial high-resolution CT scan showing a mass at the right lacrimal sac (yellow arrow), with no bony erosion. No abnormality in middle ear. c) Coronal magnetic resonance imaging scan taken after right maxillectomy and dacryocystectomy, showing no evidence of local recurrence (T1WI). d) Axial CT scan showing right mastoid gasification well and soft tissue density lesions in the right tympanic cavity and mastoid cavity. No obvious bone absorption was showed.

Correspondence to: Dr. Hongqun Jiang, Department of OtolaryngologyHead and Neck Surgery, The First Affiliated Hospital of Nanchang University, Nanchang 330006, Jiangxi, P. R. China; Tel: 0086-13870950313; Fax: +86-7918869-2519; E-mail: jianghongqun@sohu.com

Key words: lacrimal sac, middle ear, squamous cell carcinoma, metastasis Received: June 20, 2016; Accepted: July 18, 2016; Published: July 21, 2016 


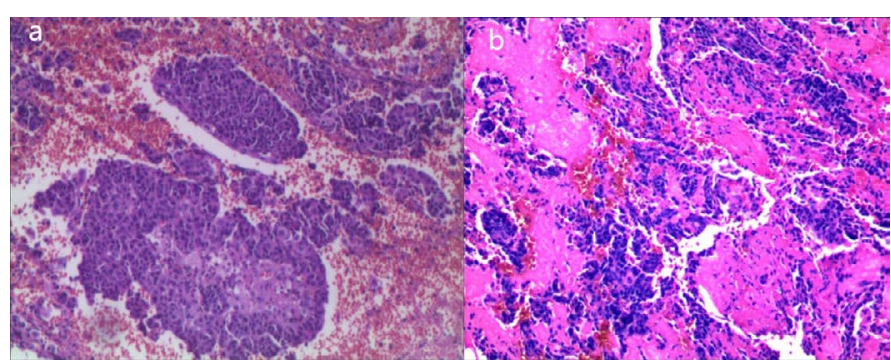

Figure 2. a) Epidermoid carcinoma of the lacrimal sac (Hematoxylin-eosin stain, $\times 100$ ). b) Epidermoid carcinoma of the middle ear(Hematoxylin-eosin stain, $\times 100$ ).

However, three and a half years after the dacryocystectomy procedure, the patient consulted our hospital for purulent with blood discharged from the right ear, gradual hearing loss and tinnitus during the previous one year. She was diagnosed with chronic purulent otitis media of the right ear following a CT scan before surgery in our hospital (Figure1d). Otological examination revealed that granulomatous tissues filled the right external auditory canal. CT scans revealed right mastoid gasification well and some soft tissue density lesions in the tympanic cavity and mastoid cavity. The ossicles were intact and showed no obvious bone absorption. No obvious abnormality was showed in the adjacent brain parenchyma of temporal lobe. This patient was diagnosed with chronic supportive otitis media before operation.

A radical right mastoidectomy was performed under general anesthesia. Intraoperative frozen sections of lesions in tympanic cavity revealed epidermoidcarcinoma (Figure2b). Immunohistochemistry for HPV marker showed negative for all of high-risk HPV strains 16 and 18 and low-risk HPV strains 6 and 11. Finally, the patient was diagnosed as SCCME, and recommended to do radiotherapy. No recurrence or metastasis was observed at the 6-month follow-up.

\section{Discussion}

This case of squamous cell carcinoma shows several unusual characteristics: the lacrimal sac is a rare site of squamous cell carcinoma, and SCCME is also rare. SCCME appeared after lacrimal sac malignant has been never described in the literatures. In our case, immunohistochemistry of the lacrimal sac tumor tissue multiple HPV types showed positive for high-risk HPV strains 16, 18 and negative for low-risk HPV strains 6 and 11. So infection of HPV may play an important role in the etiology. Serum HIV test was negative in our case. After medial maxillectomy and dacryocystectomy, the subsequent treatments of chemotherapy and radiotherapy the patient had a good recovery. No Lacrimal sac tumor in situ recurred as yet.

Although infection of HPV is also the possible cause of SCCME, immunohistochemistry analysis of middle ear tumor tissue showed negative for all of high-risk HPV strains 16,18 and low-risk HPV strains 6 and 11. Chronic otitis media is one of the etiological factors in SCCME. But in our case, the patient has no history of chronic otitis media. In the process of diagnoses, the results of preoperative CT shown for benign lessions. So she was mistaken as chronic supportive otitis media at first. But diagnosis of SCCME was confirmed by intraoperative frozen and postoperative pathology, which consistent with her history of lacrimal sac carcinoma pathology with the same side. In addition, although ear symptoms appeared 30 months after medial maxillectomy and dacryocystectomy, it might take a long time from onset to clinical symptoms. So, we speculate the SCCME may arise from the lacrimal sac carcinoma in a slow process, Several other possibilities may also explain the nature of the SCCME: First, it is possible that the SCCME arose de novo, independently in squamous cell carcinoma of lacrimal sacs, postoperative radiation may lead to the middle ear malignant tumor. A second possibility is that squamous cell carcinoma of lacrimal sacs could have led to seeding of the tumor on the ipsilateral middle ear. After receiving a radical mastoidectomy and radiotherapy, the patient have a good recovery within 6-month follow-up. Clinicians should take into account the possibility of distant metastasis in otitis media patients with a history of malignancy.

\section{Acknowledgments}

This study was supported by the first affiliated hospital of Nanchang university.

\section{References}

1. Parmar DN, Rose GE (2003) Management of lacrimal sac tumours. Eye (Lond) 17: 599-606. [Crossref]

2. Stefanyszyn MA, Hidayat AA, Pe'er JJ, Flanagan JC (1994) Lacrimal sac tumors Ophthal Plast Reconstr Surg 10: 169-184. [Crossref]

3. Schenck NL, Ogura JH, Pratt LL (1973) Cancer of the lacrimal sac. Presentation of five cases and review of the literature. Ann Otol Rhinol Laryngol 82: 153-161. [Crossref]

4. Sjö NC, von Buchwald C, Cassonnet P, Flamant P, Heegaard S, et al. (2007) Human papillomavirus: cause of epithelial lacrimal sac neoplasia? Acta Ophthalmol Scand 85: 551-556. [Crossref]

5. Gidley PW, Roberts DB, Sturgis EM (2010) Squamous cell carcinoma of the temporal bone. Laryngoscope 120: 1144-1151. [Crossref]

6. Jin YT, Tsai ST, Li C, Chang KC, Yan JJ, et al. (1997) Prevalence of human papillomavirus in middle ear carcinoma associated with chronic otitis media. $\mathrm{Am} \mathrm{J}$ Pathol 150: 1327-1333. [Crossref]

7. Tsai ST, Li C, Jin YT, Chao WY, Su IJ (1997) High prevalence of human papillomavirus types 16 and 18 in middle-ear carcinoma. Int J Cancer 71: 208-212. [Crossref]

8. Leong SC, Youssef A, Lesser TH (2013) Squamous cell carcinoma of the temporal bone: outcomes of radical surgery and postoperative radiotherapy. Laryngoscope 123: 2442-2448. [Crossref]

9. Bacciu A, Clemente IA, Piccirillo E, Ferrari S, Sanna M (2013) Guidelines for treating temporal bone carcinoma based on long-term outcomes. Otol Neurotol 34: 898-907. [Crossref]

Copyright: (C2016 Li Q. This is an open-access article distributed under the terms of the Creative Commons Attribution License, which permits unrestricted use, distribution, and reproduction in any medium, provided the original author and source are credited. 